\title{
A Study on the Relationship between the Development of Social Insurance Industry and Economic Growth in China
}

\author{
Qiming Zhao ${ }^{1, \text { a }}$, Dan Cheng ${ }^{2, \mathrm{~b}}$ \\ ${ }^{1}$ School of Applied Mathematics, Jilin University of Finance and Economics, Changchun, Jilin Province, P.R. \\ China, 130117 \\ ${ }^{2}$ Foreign economic and Trade University, Beijing, P.R. China, 100029 \\ azhaoqiming99@126.com, ${ }^{\mathrm{b}}$ chengdanfd@163.com
}

Keywords: Development of social insurance, The economic growth of China, Principal component analysis, Regression analysis

\begin{abstract}
This paper studies China's social insurance industry development and economic growth in China from 2006 to 2015 and the current situation of the relationship between the two, using the method of principal component analysis on the level of development of the ten years of China's social insurance industry to make evaluation, to establish a regression model between China's social insurance industry development and the level of economic growth, to put forward feasible suggestions.
\end{abstract}

\section{Introduction}

Social insurance is an important part of China's social security system. Social insurance also includes endowment insurance, unemployment insurance, medical insurance, industrial injury insurance and maternity insurance. Social security system, so that some social vulnerable groups can be disabled to receive certain subsidies, effectively guaranteeing their basic life. Whether the social insurance system is perfect or not reflects the development level of a country. At the same time, social insurance is also a powerful reflection of human civilization. It is a symbol of a country's modernization. Only by forming a sound social security system can the country achieve long-term stability and provide a good social environment for the rapid development of economy.

In the past decade, China's social insurance industry has developed rapidly, and the coverage of social insurance has become wider and wider. It basically covers the workers of urban enterprises or institutions. The number of people participating in social insurance has risen steadily. The amount of social insurance has also increased year by year. The data show that the total premium in 2006 was 564.144 billion yuan, in 2015. China's total premium has reached 2428.25 billion yuan, four times the total premium in 2006. From a macro perspective, China's GDP in 2006 was 2190.28 billion yuan, China's GDP in 2015 was 6826.31 billion yuan, China is the second largest economy in the world, and the insurance amount in 2006 accounted for China's domestic economy. 2.57\% of GDP, and the proportion of insurance to GDP in 2015 is as high as 3.56\%. This shows that China's economy has achieved a huge leap in the past decade, the social insurance industry has not only achieved rapid development, but also played an increasingly important role in economic growth.

Based on the above analysis, it is particularly important to study the contribution of the social insurance industry to economic growth. This paper studies the development of the social insurance industry and the relationship between the development of the social insurance industry and economic growth, so as to correctly understand the role of social insurance, in order to improve the social insurance system and promote better social and economic development. It is practical and feasible. 


\section{Methodology}

\subsection{Principal component analysis of the development level of China's social insurance industry}

Using SPSS to centralize the original data, the total variance explanation of principal component analysis and factor load matrix of social insurance development level in China from 2006 to 2015 are obtained, and then the comprehensive score of social insurance development level in the past decade is calculated. Bringing standardized data into the principal component expression can get a comprehensive score from 2006 to 2015.

From the score, we can see that the social insurance industry in China has developed rapidly in the past 10 years. The comprehensive score calculated by standardized data has changed from negative value to positive value. The larger the value, the higher the development level of social insurance industry. Since the 16th National Congress of the CPC, China has established a social insurance system consisting of five basic types of insurance, namely, old-age insurance, medical insurance, unemployment insurance, work-related injury insurance and maternity insurance. Each type of insurance has developed to varying degrees. The comprehensive score in Table 4 is the comprehensive development level of all kinds of insurance. Since 2011, the pilot of the new rural social endowment insurance has gradually expanded, covering a wider area. At the same time, the pilot of urban residents' social endowment insurance has been officially launched. By the end of the year, the number of people participating in social endowment insurance has reached 360 million, so the comprehensive score in 2011 has become positive. The development of social insurance industry is also closely related to economic growth. The continuous development of China's economic level is the result of the comprehensive influence of various factors. But the development of social insurance industry has really become a powerful force to promote economic development. The social insurance industry provides a good environment for economic growth. On the other hand, economic growth can further promote the establishment, development and improvement of the insurance system, laying a foundation for the development of the insurance industry. Therefore, in order to study the relationship between the two, this paper establishes a regression model of the level of social insurance development and economic growth.

\subsection{Regression analysis of the relationship between the development of social insurance industry and economic growth in China}

According to the classical macroeconomic theory, economic growth is mainly driven by final consumption, investment and net exports. The sum of government investment and private investment is total investment, the sum of household consumption and government consumption is total final consumption, and exports are reduced to net exports of goods and services. This is also the method of expenditure to calculate GDP. Therefore, in addition to the development level of social insurance industry, the independent variables selected in the study of China's economic growth should include consumer spending, government expenditure, investment, net exports. Using the data of 2006-2015, taking the value of GDP Y as the explanatory variable, taking consumption $\mathrm{C} 1$, government expenditure $\mathrm{G}$, total investment $\mathrm{I}$, total net export $\mathrm{NX}$, social insurance development level as the explanatory variable, the regression model is established.

$$
Y=-7536.73+0.613 C 1+1.354 I+1.354 N X+0.857 G-1234.405 F
$$

The regression results show that the model's resolvability coefficient $R^{2}=0.9998$, and the revised resolvability coefficient $\bar{R}^{2}=0.9997$, which shows that the regression model fits well. The model passes $\mathrm{F}$ test, indicating that the overall linear relationship of the model is more significant, but the coefficients before the scores of resident consumption, government expenditure and social insurance industry development level are all greater than 0.05 . Under the significance level of 0.05 , all the variables failed to pass the test, indicating that these variables alone have no significant impact on the interpreted variables, which is inconsistent with the economic significance. The problem of multiple collinearity is solved by stepwise regression, and the regression equation is:

$$
Y=77212.02+3.71 G+8837.27 F+0.72 I
$$


The conclusion of the above analysis proves that there is a positive correlation between the development of China's social insurance industry and China's economic growth, that is, the development of China's insurance industry will promote China's economic growth. Quantitative analysis can be made from the model. With each increase in the comprehensive score of China's insurance industry, China's GDP will increase by 883.727 billion yuan. . It is tested that there is no first order correlation Heteroscedasticity in this model.

\section{Conclusions and recommendations}

\subsection{Conclusions}

Various types of insurance in China's social insurance industry have varying degrees of development. This paper finds that since 2006, China's social insurance system has been constantly improved, the fund account has been constantly improved, the total fund income has risen substantially, and the fund income of the five major types of insurance, such as endowment insurance, unemployment insurance, basic medical insurance, work-related injury insurance and maternity insurance, has shown an upward trend. This trend is not only manifested. On the absolute value, and on the relative value. Among the five types of insurance, pension insurance has the largest fund income and expenditure, partly because China is a populous country. In recent years, China is facing a serious problem of population aging, the proportion of the elderly is gradually increasing, and the absolute value of the elderly population is relatively large; the other part of the original. Because of the gradual improvement of the quality of our population, China pays more attention to the harmonious development of civilization, and constantly improves the social security system, forming a wider coverage of the social security system, so that more people enjoy the most basic protection. Relatively speaking, although the base of birth insurance is small, the growth rate of birth insurance is the fastest. In the future development process, birth insurance will have a better development.

China's economic growth is slowing down, but China's economy is improving steadily. Since the reform and opening up, China's economy has been developing rapidly, and has maintained a relatively fast speed of development, making China overtake the developed countries in Europe in just a few decades and become the second largest economy in the world. The growth rate has reached the lowest level in ten years since 2006, with an annual growth rate of $6.9 \%$. Relevant departments announced that China's economic growth target for the whole year 2017 is 6\% - 6.5\%. In terms of economic form, it is more and more difficult for China to achieve the goal of higher growth rate because of its large economic aggregate. China has begun to take healthy development as the primary goal. But this does not mean that China's economy is going downhill. In this field, China's high-tech industry still has great potential for development.

The development of China's social insurance industry promotes China's economic growth. From the regression model established above, we can see that the development of China's social insurance industry can indeed promote China's economic growth, the use of principal component analysis method to calculate the comprehensive level of social insurance industry development score increased by one point, China's economic growth rate increased by 0.6 percentage points, although the impact is less than. Consumption and net exports, but China's social insurance industry can become a focus to promote China's economic growth. From the perspective of social insurance fund expenditure in China, it shows a trend of increasing year by year. With the continuous development and improvement of the social insurance industry, it plays an increasingly important role in economic compensation and financing. It is an effective way to obtain social capital and promote economic growth.

\subsection{Recommendation}

We should strengthen the management of social insurance funds. In macro-economy, social security system, as a very effective economic stabilizer, can automatically suppress depression during economic recession, and social insurance as an effective way of social security, China's 
social insurance is a compulsory social insurance fund established by the state through legislation, it is the largest with commercial insurance. The difference is that it is not for profit-making purposes, China's current partial accumulation system, this system can be a good solution to the population aging and the initial high premium system of contradictions, but also facing the management of the fund and the problem of preservation and appreciation of value. Since the 1980s, there have been some new changes in the management of social insurance funds. First, social insurance funds are open to private fund management companies. Second, China has made diversified investments. Insurance differs from other financial products in that it provides risk protection, which is the value of the insurance industry and its special advantages. Therefore, the insurance company should pay attention to the creation and promotion of the intrinsic value, not only pursue the scale and speed, but pay more attention to the quality and effect of development, effectively play the role of insurance as an economic stabilizer, escort the steady economic growth.

Improve the income of social insurance fund. China's social insurance fund is mainly raised through the society. China has a large population and a considerable amount of social insurance fund. How to use such a large amount of funds to invest in order to obtain higher returns and promote economic development is a major issue. Social insurance provides the most basic living security for the insured. The state takes part of the premium collected as retained funds to meet the needs of normal payment. The rest of the premium is used for various specific investments to increase income and promote the circulation of funds. The state should formulate a relatively perfect retention system for social insurance funds, which can be used for national construction and private credit within a certain range of risks, so as to increase the income of insurance funds.

Expand the scope of social insurance. China's social insurance is to maintain the reproduction of labor force. The insurance fund comes from the payment and financial support of the employer and the individual laborer. The insurance object is limited to the employees, excluding other social members. However, there are a large number of peasant workers in China, who are also laborers, but their lives are not yet complete. To be sure, China should establish a security system for these farm workers, mainly endowment and medical insurance. Their insurance accounts can be paid by themselves, and the state subsidies can be part of it, so as to form a social insurance system benefiting the broader masses of the people.

\section{Acknowledgements}

Educational reform project of Jilin Provincial Department of Education, Soft science project of Jilin science and Technology Department [20170418068FG].

\section{References}

[1] Ramanathan, R. Introductory Econometrics with Applications, 4th ed. [M]. The Dryden Press,1998.

[2] H. Pang. Econometrics. $2^{\text {nd }}$ ed. [M]. Beijing: Science Press, 2010.6.(In Chinese).

[3] P. Xiao, L. Y. Li. and J. Su. The threshold of insurance industry development and the dynamic equilibrium of China's economic growth [J].Journal of Shanxi finance and economics university,2015, 37(10):33-43. (In Chinese).

[4] Peter Haiss, Kjell Sümegi. The relationship between insurance and economic growth in Europe: a theoretical and empirical analysis [J]. Empirica. 2008 (4):23-28.

[5] Giacomo Corneo, Marko Marquardt. Public pensions, unemployment insurance, and growth[J] . Journal of Public Economics. 2000 (2):15-19.

[6] H. Z. Zhou. Research on the relationship between insurance industry development and economic growth [J]. Management World. 2008(11):170-171. (In Chinese). 